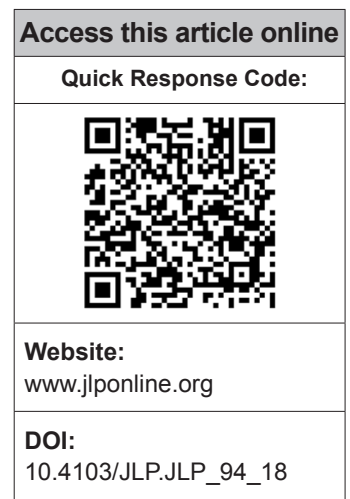

Department of Pathology, Niloufer Hospital for Women and Children, Hyderabad, Telangana, India

Address for correspondence:

Dr. Abdul Aleem Mohammed, Hno:19-2-11/142/A, Bilal Nagar, Kala Pathar,

Hyderabad - 500 053,

Telangana, India

E-mail: dr.abdulaleem1@ gmail.com

Submission: 14-07-2018 Accepted: 09-02-2019

\title{
Abnormalities of the intestinal pacemaker cells, enteric neurons, and smooth muscle in intestinal atresia
}

\author{
Radhika Krishna OH, Mohammed Abdul Aleem, Geetha Kayla
}

\section{Abstract:}

BACKGROUND: Small bowel atresia is a congenital disorder that carves a substantial morbidity. Numerous postoperative gastrointestinal motility problems occur. The underlying cause of this motility disorder is still unclear. Interstitial cells of Cajal (ICC) play a major role in gastrointestinal motility.

AIMS AND OBJECTIVES: To investigate the morphological changes of enteric nervous system and ICC in small bowel atresia.

MATERIAL AND METHODS: Resected small bowel specimen from affected patients $(n=15)$ were divided into three parts (proximal, distal, atretic). Standard histology and immunohistochemistry with anti C-KIT receptor antibody (CD117), calretinin and $\alpha$-SMA was carried out. The density of myenteric ICCs in the proximal, atretic and distal parts was demonstrated by CD 117 while Calretinin was used for ganglion cells and nerve bundles, $\alpha$-SMA highlighted muscle hypertrophy.

RESULT AND CONCLUSION: The proximal and distal bowel revealed clear changes in the morphology and density of enteric nervous system and interstitial cells of Cajal..

Key words:

C-kit, enteric nervous system, interstitial cells of Cajal, intestinal atresia

\section{Introduction}

Small bowel atresia is a congenital Sisorder that carries a substantial morbidity. ${ }^{[1,2]}$ The incidence of small bowel atresia is higher than large bowel atresia and varies between $1: 300$ and $1: 3000 \cdot{ }^{[3]}$ Newborns with intestinal atresia are operated soon after birth. Intestinal dysmotility is an important problem in the postoperative management of patients with jejunoileal atresia. The alterations of the neural and muscular elements and the extent of histological changes proximal and distal to atresia may contribute to postoperative intestinal dysmotility. ${ }^{[4]}$ Various problems may occur as prolonged a dynamic ileus and need for total parental nutrition. ${ }^{[1,2]}$ Operative techniques and postoperative parenteral

This is an open access journal, and articles are distributed under the terms of the Creative Commons Attribution-NonCommercial-ShareAlike 4.0 License, which allows others to remix, tweak, and build upon the work non-commercially, as long as appropriate credit is given and the new creations are licensed under the identical terms.

For reprints contact: reprints@medknow.com nutrition have improved the outcome, but prolonged intestinal motility disorders remain common in the postoperative period, even in the absence of any mechanical lesions. ${ }^{[2]}$ Etiology of small bowel atresia remains unclear. ${ }^{[3]}$ One of the two accepted theories is the lack of recanalization of solid organ during late stage of intestinal development. ${ }^{[5]}$ Another concept is late intrauterine mesenteric vascular accident. ${ }^{[3]}$

Basically, normal gastrointestinal motility depends on the coordinated function of the enteric nervous system (ENS), intestinal smooth muscle, and interstitial cells of Cajal (ICC) ${ }^{[3]}$ In this study, we have analyzed all these three components of enteric motility in the proximal and distal segments of small bowel atresia and tried to elucidate the pathogenesis of postoperative enteropathy. We confined this study specifically to ileal atresia which is the most common.

How to cite this article: Radhika Krishna $\mathrm{OH}$, Aleem MA, Kayla G. Abnormalities of the intestinal pacemaker cells, enteric neurons, and smooth muscle in intestinal atresia. J Lab Physicians 2019;11:180-5. 


\section{Materials and Methods}

This is a 3-year prospective study (August 2014-August 2017) conducted at the Department of Pathology at a Tertiary Care Pediatric Referral Hospital in South India. The resected specimen of small bowel atresia (Type II, III $b, I V)$ was divided into three parts as proximal (P), distal (D) and atretic (A) segments. In Type I and Type IIIa atresia, only proximal and distal segments were available for study; and hence, the study was taken up only on proximal and distal resected margins for uniformity.

The specimens were fixed in neutral buffered formalin and processed into paraffin blocks. Paraffin-embedded tissues were sectioned at $2-4 \mu \mathrm{m}$ followed by drying at $37^{\circ} \mathrm{C}$ in an incubator overnight. Before immunohistochemical (IHC) staining, the paraffin sections were dewaxed for $10 \mathrm{~min}$ in xylene, followed by $10 \mathrm{~min}$ in acetone and $10 \mathrm{~min}$ in acetone/Tris-buffered saline (TBS; 1:1). After this treatment, the slides were washed in TBS. Antigen demasking was done by microwave treatment, and the slides were left to cool down then were again washed in TBS.

Standard histology using hematoxylin and eosin was performed. The changes in the mural compartment, the smooth muscle of the bowel were assessed, and simultaneously IHC with alpha-smooth muscle actin $(\alpha-S M A$, monoclonal mouse anti-human SMA clone $1 \mathrm{~A} 4$, and DAKO) was also studied for comparison. The neural component was studied in the myenteric and submucosal areas. The myenteric plexuses of ganglion cells were assessed on histology and IHC by calretinin (monoclonal mouse anti-human calretinin clone DAK-Calret 1, DAKO) was simultaneously performed and compared. The number of cells in a ganglion, relative distribution of smaller and larger ganglia was recorded. The presence of more than seven ganglion cells per ganglia was considered as giant ganglia. Increased density of ganglia per histological section was also documented. All these findings were correlated with IHC for ganglion cells using calretinin. The pacemaker component was studied by IHC with CD117 (anti-C-kit receptor 1 in 600 dilution, Polyclonal Rabbit Anti-Human CD117, DAKO) was employed, and their distribution was tabulated. The evaluation of the IHC staining results was focused on the proximal and distal parts of the resected ileum.

\section{Results}

Our study included resected small bowel ileal segments from 18 newborn patients over a period of 3 years. Histology and IHC sections were evaluated by two pathologists using light microscopy under high power $(\times 40)$. The evaluation of the IHC staining results was focused on the proximal and distal margins of the resected ileum.

The type of atresia was determined according to the classification of Grosfeld et al. ${ }^{[6,7]}$ In the present study, Type II atresia was the most common type $(n=7 / 18)$ [Figure 1 and Table 1]. On H and E, the intestinal muscularis propria was evaluated for hypertrophic changes [Figure 2]. The number and distribution of ganglion cells in the myenteric and submucosal plexuses were assessed. Immunostaining with $\alpha$-SMA and calretinin was used for assessing the muscular and neuronal components. C-kit (CD117) positive cells, i.e., ICC and mast cells were studied in each part of the resected bowel. Since the quantitative analysis of IHC was not possible, semi-quantitative scoring for CD117-positive ICC was performed and analyzed [Table 2].

Proximal and distal bowel showed clear differences in histomorphology, density of enteric neurons, and ICC. We found prominent circular muscle hypertrophy in the proximal segment as compared to the distal bowel segment which was also confirmed by decreased immunostaining of $\alpha$-SMA in all 18 cases [Figure 3]. Increased frequency and density of ganglion cells was noted in the bowel segment proximal to the atresia as compared to the distal bowel segment on histology and immunostaining by calretinin [Figure 4]. Increased number of ganglia and presence of giant ganglia was confirmed by IHC in 13 out of 18 proximal and 11 out of 12

Table 1: Types of atresia in the present study classified according to Grosfeld et al. classification

\begin{tabular}{lc}
\hline Type of atresia & Number of cases \\
\hline Type I & 2 \\
Type II & 7 \\
Type IIla & 4 \\
Type IIIb & 4 \\
Type IV & 1 \\
Total & 18 \\
\hline
\end{tabular}

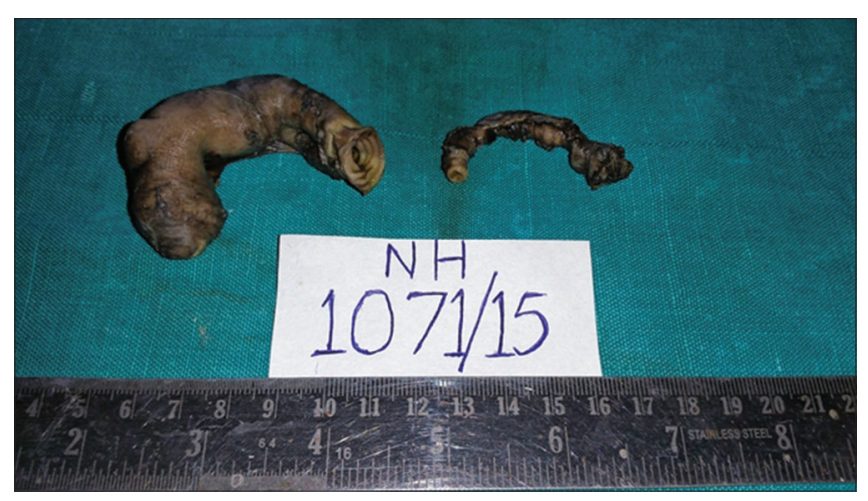

Figure 1: Resected gross specimen of ileal atresia with atretic segment and dilated proximal segment 


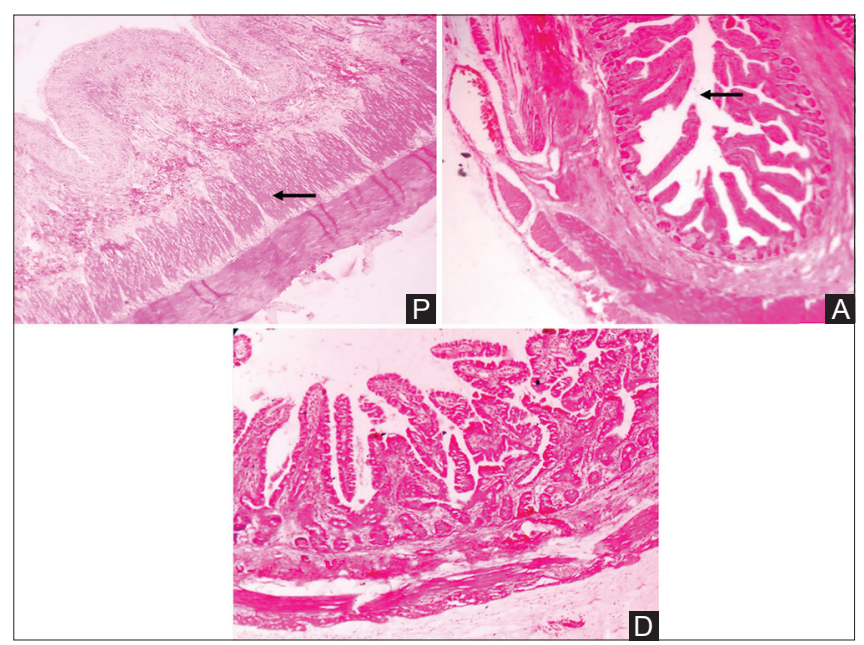

Figure 2: Proximal segment shows hypertrophy of circular and longitudinal smooth muscle (Arrow). Atretic segment shows obliteration of lumen (Arrow) $(P=$ Proximal segment, $A=$ Atretic segment, $D=$ Distal segment, $\mathrm{H}$ and $\mathrm{E}$, scanner view $\times 40$ )

atretic segments while the normal distribution of ganglia was seen in 16 out of 18 cases. Significant decrease in the ICC was noted in the proximal segment as compared to the distal segment by CD117 immunostaining [Figure 5]. The density of ICCs within the myenteric plexus was clearly reduced in the proximal bowel in 14 out of 18 cases and 10 out of 12 atretic segments, whereas some ICCs were found in the circular and longitudinal muscle layer. The anti-CD117 immunoreaction revealed numerous mast cells within the proximal bowel. The distal bowel had a normal distribution of ICCs within the myenteric plexus and muscular layers in 16 out of 18 cases while showing normal number and distribution of mast cells as an internal control. IHC results were tabulated and analyzed in Table 3.

\section{Discussion}

Congenital intestinal atresia is a common gastrointestinal tract malformation. At present, a mesenteric vascular accident during fetal life is considered to be the main cause of congenital intestinal atresia, and surgical resection is the only method of treatment. ${ }^{[4,5,8]}$

This study, the first of its kind at our institute, revealed clear variations in the muscular, neuronal, and pacemaker components between the proximal and distal segments of ileal atresia. We found prominent circular muscle hypertrophy and increased frequency and density of ganglion cells in the proximal part of the atresia findings confirmed by $\alpha$-SMA and calretinin immunostaining. Decreased $\alpha$-SMA staining was noted in the hypertrophic muscle significant decrease in the ICC was noted in the proximal segment as compared to the distal on CD117 immunostaining.

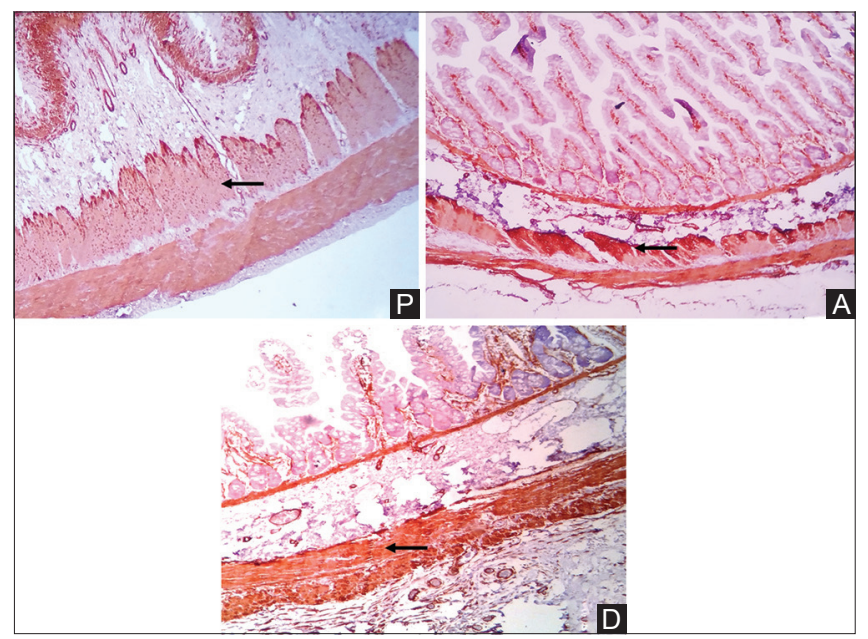

Figure 3: Immunohistochemistry with alpha-smooth muscle actin shows proximal segment with circular smooth muscle hypertrophy and decreased intensity of alpha-smooth muscle actin staining as compared with the distal segment (Arrow) $(P=$ Proximal segment, $A=$ Atretic segment, $D=$ Distal segment. Alpha-smooth muscle actin immunohistochemical, scanner view $\times 40$ )

Table 2: Semi-quantitative scoring for CD117

\begin{tabular}{|c|c|c|}
\hline Score & C-kit (CD117) expression & Observation/inference \\
\hline- & No expression & No staining \\
\hline+ & Low expression & $\begin{array}{l}\text { Few neuronal fibres and } \\
\text { cells/few ICC }\end{array}$ \\
\hline++ & Moderate expression & $\begin{array}{l}\text { Numerous neuronal fibres and } \\
\text { cells/numerous ICC }\end{array}$ \\
\hline+++ & High expression & $\begin{array}{l}\text { Dense networks of neuronal } \\
\text { fibres and cells/dense network } \\
\text { of ICC }\end{array}$ \\
\hline
\end{tabular}

ICC=Interstitial cells of Cajal

It has been well documented that muscular hypertrophy which is thought to result from prenatal intestinal obstruction is found exclusively in the circular muscle of the distended proximal intestinal segment. ${ }^{[9-11]}$ Previous studies indicate that muscular adenosine triphosphate activity is reduced in the hypertrophic muscle layer in the proximal intestine of the ileal atresia. ${ }^{[9-11]}$ It is unclear whether the hypertrophy of circular muscle layer results from the real increase in muscle fibers or hypertrophy of cells. It can be deduced that decreased staining intensity for $\alpha$-SMA in hypertrophic circular muscle is caused by altered expression of contractile protein in smooth muscle cells or delayed development of smooth muscle cells. $\alpha$-SMA is one of the major contractile proteins associated with intestinal motility ${ }^{[12]}$ It is also supposed that these muscular $\alpha$-SMA changes may be associated with the junctional disorder of the circular muscle and therefore a decreased motility as atretic segment showed thinning of the muscular propria. The distal segment was found to have normal musculature.

In utero vascular insults have been shown to cause ileal atresia. ${ }^{[13,14]}$ Tibboel et al. studied effects of temporary ischemia and general hypoxia on intestines of chick 
Table 3: Immunohistochemical summary and analysis for proximal, atretic and distal segments using CD117, calretinin and $\alpha$-smooth muscle actin

\begin{tabular}{|c|c|c|c|}
\hline & Proximal (18) & Atretic segment (12) & Distal segment (18) \\
\hline \multirow[t]{2}{*}{ C-Kit (CD117) } & $-/+$ & $-/+$ & $++/+++$ \\
\hline & Decreased ICCs in $14 / 18$ & Decreased ICCs in $10 / 12$ & Normal distribution of ICCs in $16 / 18$ \\
\hline $\mathrm{CR}$ & $\begin{array}{l}\text { Increased number of ganglia and } \\
\text { presence of giant ganglia in } 13 / 18\end{array}$ & $\begin{array}{l}\text { Increased number of ganglia and } \\
\text { presence of giant ganglia in } 11 / 12\end{array}$ & Normal distribution of ganglia in $16 / 18$ \\
\hline$\alpha-S M A$ & $\begin{array}{l}\text { Hypertrophic circular smooth muscle, } \\
\text { less intensity of SMA staining in } 18 / 18\end{array}$ & $\begin{array}{l}\text { Normal distribution of SMA, no } \\
\text { hypertrophy in } 10 / 12\end{array}$ & $\begin{array}{l}\text { Normal distribution of SMA, no hypertrophy in } \\
17 / 18\end{array}$ \\
\hline
\end{tabular}

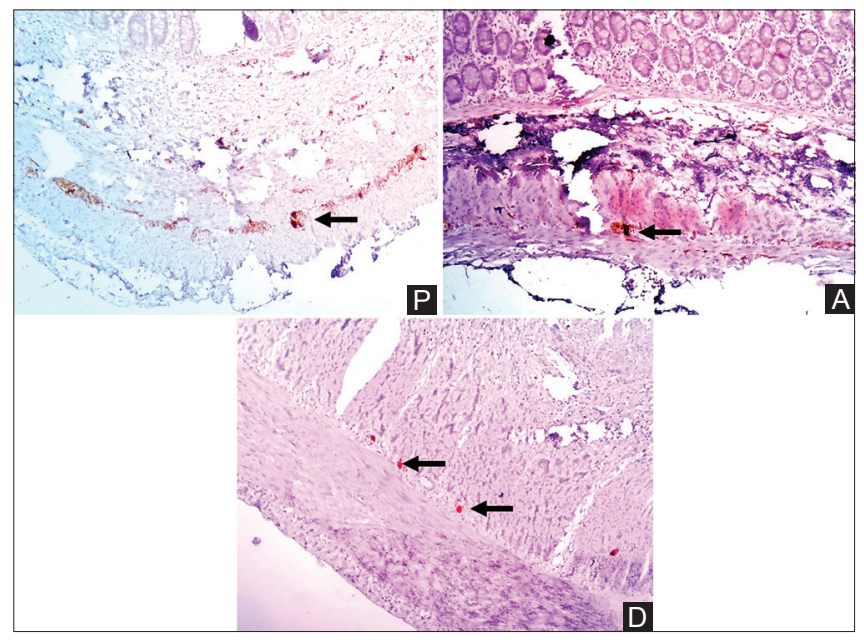

Figure 4: Immunohistochemistry with calretinin shows mature ganglion cell cytoplasm and the surrounding nerve fibers. Distal segment and atretic segment showed reduced number and intensity of ganglion cells as compared with the proximal segment (Arrow) $(P=$ Proximal segment, $A=$ Atretic segment, $D=$ Distal segment, calretinin $\mathrm{IHC}$, scanner view $\times 40$ )

embryos and concluded that disruptions of circulation on the mesenteric blood vessels during fetal hypoxia leads to atresia with structural abnormalities in the muscle coats. A causal relationship between vascular accidents in utero and muscular changes in atresia is established. ${ }^{[14]}$

The postoperative dysmotility has been found frequently in cases of a severely dilated proximal segment. Ozguner reported that the proximal segment showed changes in ganglion cells and attributed it to the uterine intravascular accident. ${ }^{[4]}$ Tepas et al. experimentally produced ileal atresia in fetal lambs and showed dilatations of proximal segment induces involution and lysis of ganglion cells after initial hyperplasia of myenteric ganglia and irreversible distension continues. ${ }^{[11]}$ Masumoto et al. found decrease in the neuronal cells in their study on jejunal atresia. ${ }^{[12]}$ Hamdy et al. reported decreased ganglion cells in the proximal dilated segment. ${ }^{[15]}$ Di Nardo et al. however indicated in their case report of small bowel atresia that their case was initially diagnosed as hypergangliosis and later enteric neuropathy. ${ }^{[16]}$

Gfroerer et al. found the ganglion cells to be increased in the dilated proximal segment and some of them

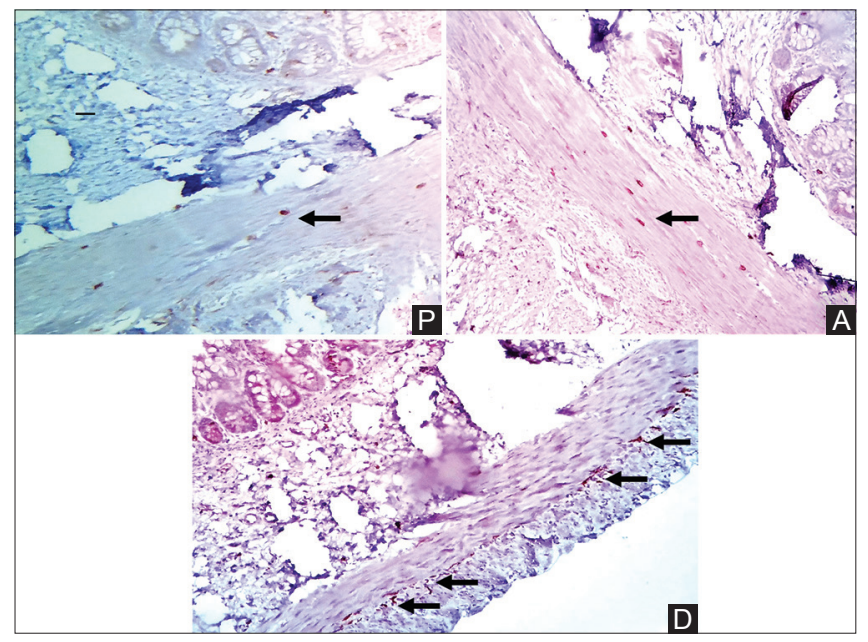

Figure 5: Immunohistochemistry with Anti C-kit immunohistochemical revealed proximal segment and atretic segment with low expression for Interstitial cells of Cajal while moderate to high expression was noted in distal segment (Arrow). Interstitial cell of Cajal are stellate cells with long and short processes seen circular and longitudinal muscle layers. Mast cells can be seen scattered in proximal and atretic segments which are $C D 117$ positive as internal control $(P=$ Proximal segment, $A=$ Atretic segment, $D=$ Distal segment. Anti C-kit IHC, scanner view $\times 40$ )

were larger with increased number of ganglion cells. ${ }^{[3]}$ Their range concluded 756 ganglion cells per $10 \mathrm{~mm}$ of smooth muscle as the normal neuronal density of human myenteric plexus from their elaborate study on ganglion cell distribution.

Our study also showed increased number of ganglion cells in the myenteric plexus. Dysmotility of the bowel in the postoperative period has been attributed to alterations in the myenteric plexus of the proximal bowel. ${ }^{[17]}$ These hypertrophic ganglion cells can be considered due to adaptive phenomena to long-standing prenatal bowel obstruction. Several experimental models have been instrumental in supporting the concept that adaptive changes in the ENS occur proximal to obstructed gut. ${ }^{[18-25]}$ These studies revealed increased density and size in both myenteric ${ }^{[20-23,25]}$ and submucosal neurons. ${ }^{[23-25]}$ Another observation is delayed maturation of ENS within the distal bowel during fetal development in cases with small bowel atresia. ${ }^{[26,27]}$ It may be speculated that with the restoration of bowel continuity does maturation of ENS occur. Distal bowel in our study did not show hypergangliosis. 
ICC is the pacemaker cells of the bowel and plays a prominent role in bowel motility. Immunoreactive ICCs are stellate cells with many long and short processes. Mast cells are rounded C-kit-positive cells that can be used as internal control for CD117 in the gut. ${ }^{[28]}$ The role of the ICC in pacemaker activity in the gut and in overall gut motility has been well established in animal models. Their intercalation between enteric nerve varicosities and smooth muscle cells makes it also very likely that ICC have a role in neurotransmission, as envisioned by Cajal. ${ }^{[29]}$

In the small bowel immunoreactive cells are found in highest numbers between circular and longitudinal layers of muscularis externa in close relation to the myenteric plexus of Auerbach. Individual immunoreactive ICC is found between muscle cells, especially the outer part of the circular muscle layer and rarely in the longitudinal muscle layer. No ICC is seen in submucosa. ${ }^{[28]}$ The key role played by these cells in the generation of pacemaker activity makes it likely that a proportion of hitherto unexplained gut motility disorders are caused by functional or structural abnormalities in ICC. ${ }^{[30]}$ Data are accumulating in studies of various motility disorders in humans, where decreased numbers or frank absence of ICC are frequently observed. Whereas in the pediatric population, some of these ICC abnormalities are clearly related to a developmental delay of these cells, the causes and effects of ICC damage and/or loss in adults are less evident. ${ }^{[29]}$ In some cases, it may be possible that loss of IHC staining for C-kit and not the actual ICC is responsible for these observations; however, the kit protein appears quite stable and is stainable even when the ICC show significant damage by electron microscopy. ${ }^{[8]}$ Hence, it is presumed that in most cases, loss of IHC staining for C-kit does identify true loss of ICC. ${ }^{[29]}$

Lower scores of ICC was found in the proximal segments in our study and higher scores in the distal segment clearly showing that there is a paucity of ICC in the proximal dilated segment and implicating their absence in etiopathogenesis of dysmotility. Some of these cases had postoperative intestinal motility issues and morbidity.

A previous animal study using partial obstruction model in the mice revealed that 2 weeks following the onset of partial obstruction, the bowel increased in diameter and hypertrophy of tunica muscularis was observed oral to the obstruction site. This disruption was accompanied by loss of electrical slow waves and responses to enteric nerve stimulation. These effects were not observed aboral to the obstruction. It was shown that removal of obstruction leads to the redevelopment of ICC networks and recovery of slow wave activity within 30 days. ${ }^{[21]}$ Neural responses recovered in 30 days. Similar repair mechanisms may occur after surgical correction of small bowel atresia. It appears that decrease in the ICC and their restoration after removal of obstruction contributes to small bowel atresia. ${ }^{[8]}$

In the three entities we studied, ICC was found to be significantly variable in the proximal and distal segment. A routine performance of CD117 in the proximal resected margin may be essential in all the cases of ileal atresia to score the ICC and predict the outcome. Further studies of scoring ICC at different levels of the proximal segment are needed for better understanding this hypothesis.

\section{Conclusion}

The proximal and distal bowel revealed clear changes in the morphology and density of ICC. Long term high-pressure load in atresia may lead to changes in the distribution of ICCs leading to deterioration of motility in proximal segment. Furthermore, the decreased number of neuronal cells and fibers in atresia may contribute to delayed neuronal development. More studies are needed to determine the exact length of proximal bowel that needs to be resected.

The routinely studied histological features do not contribute to the understanding of the postoperative dysmotility in small bowel atresia. A defective expression of CD117-positive ICC cells in the proximal bowel may be useful in the understanding postoperative dysmotility. It is easier and cost-effective option with significant postoperative prognostic value.

\section{Financial support and sponsorship}

Nil.

\section{Conflicts of interest}

There are no conflicts of interest.

\section{References}

1. Stollman TH, de Blaauw I, Wijnen MH, van der Staak FH, Rieu PN, Draaisma JM, et al. Decreased mortality but increased morbidity in neonates with jejunoileal atresia; a study of 114 cases over a 34-year period. J Pediatr Surg 2009;44:217-21.

2. Dalla Vecchia LK, Grosfeld JL, West KW, Rescorla FJ, Scherer LR, Engum SA. Intestinal atresia and stenosis: A 25-year experience with 277 cases. Arch Surg 1998;133:490-6.

3. Gfroerer S, Metzger R, Fiegel H, Ramachandran P, Rolle U. Differential changes in intrinsic innervation and interstitial cells of Cajal in small bowel atresia in newborns. World J Gastroenterol 2010;16:5716-21.

4. Ozguner IF, Savas C, Ozguner M, Candir O. Intestinal atresia with segmental musculature and neural defect. J Pediatr Surg 2005;40:1232-7.

5. Tandler J. Developmental history of the human duodenum in early embryonic stages. Morphol Jahrb. 1900;29:187-216.

6. Grosfeld JL, Ballantine TV, Shoemaker R. Operative mangement of intestinal atresia and stenosis based on pathologic findings. J Pediatr Surg 1979;14:368-75. 
7. Millar AJ, Rode H. Jejuno ileal atresia. In: Puri P, Hollwarth ME, editors. Pediatric Surgery. Berlin, Germany: Springer Science and Business Media; 2006. p. 213-28.

8. Wang X, Yuan C, Xiang L, Li X, Zhao Z, Jin X. The clinical significance of pathological studies of congenital intestinal atresia. J Pediatr Surg 2013;48:2084-91.

9. Doolin EJ, Ormsbee HS, Hill JL. Motility abnormality in intestinal atresia. J Pediatr Surg 1987;22:320-4.

10. Cezard JP, Cargill G, Faure C, Boige N, Mashako LM, Munck A, et al. Duodenal manometry in postobstructive enteropathy in infants with a transient enterostomy. J Pediatr Surg 1993;28:1481-5.

11. Tepas JJ, Wyllie RG, Shermeta DW, Inon AE, Pickard LR, Haller JA Jr., et al. Comparison of histochemical studies of intestinal atresia in the human newborn and fetal lamb. J Pediatr Surg 1979;14:376-80.

12. Masumoto K, Suita S, Nada O, Taguchi T, Guo R. Abnormalities of enteric neurons, intestinal pacemaker cells, and smooth muscle in human intestinal atresia. J Pediatr Surg 1999;34:1463-8.

13. Grosfeld JL. Jejunoileal atresia and stenosis. In: O'neill JA Jr., Rowe ML, Grosfeld JL, Fonkalsrud EW, Coran AG, editors. Pediatric Surgery. $5^{\text {th }}$ ed. St. Louis (Mo): Mosby; 1998. p. 1145-58.

14. Tibboel D, van Nie CJ, Molenaar JC. The effects of temporary general hypoxia and local ischemia on the development of the intestines: An experimental study. J Pediatr Surg 1980;15:57-62.

15. Hamdy MH, Man DW, Bain D, Kirkland IS. Histochemical changes in intestinal atresia and its implications on surgical management: A preliminary report. J Pediatr Surg 1986;21:17-21.

16. Di Nardo G, Stanghellini V, Cucchiara S, Barbara G, Pasquinelli G, Santini D, et al. Enteric neuropathology of congenital intestinal obstruction: A case report. World J Gastroenterol 2006;12:5229-33.

17. Watanabe $Y$, Ando H, Seo T, Katsuno S, Marui Y, Horisawa M. Two-dimensional alterations of myenteric plexus in jejunoileal atresia. J Pediatr Surg 2001;36:474-8.

18. Kapur RP. Neuropathology of paediatric chronic intestinal pseudo-obstruction and related animal models. J Pathol 2001;194:277-88.

19. Barbosa AJ, Tafuri WL. Ganglion cell number in hypertrophic colon above experimental stenosis. Braz J Med Biol Res 1983;16:165-9.

20. Brehmer A, Göbel D, Frieser M, Graf M, Radespiel-Tröger M, Neuhuber W. Experimental hypertrophy of myenteric neurones in the pig: A morphometric study. Neurogastroenterol Motil 2000;12:155-62.

21. Chang IY, Glasgow NJ, Takayama I, Horiguchi K, Sanders KM, Ward SM. Loss of interstitial cells of Cajal and development of electrical dysfunction in murine small bowel obstruction. J Physiol 2001;536:555-68.

22. Ekblad E, Sjuve R, Arner A, Sundler F. Enteric neuronal plasticity and a reduced number of interstitial cells of Cajal in hypertrophic rat ileum. Gut 1998;42:836-44.

23. Gabella G. Size of neurons and glial cells in the intramural ganglia of the hypertrophic intestine of the guinea-pig. J Neurocytol 1984;13:73-84.

24. Gálvez Y, Skába R, Vajtrová R, Frantlová A, Herget J. Evidence of secondary neuronal intestinal dysplasia in a rat model of chronic intestinal obstruction. J Invest Surg 2004;17:31-9.

25. Jew JY, Williams TH, Gabella G, Zhang MQ. The intestine as a model for neuronal plasticity. Arch Histol Cytol 1989;52 Suppl:167-80.

26. Khen N, Jaubert F, Sauvat F, Fourcade L, Jan D, Martinovic J, et al. Fetal intestinal obstruction induces alteration of enteric nervous system development in human intestinal atresia. Pediatr Res 2004; $56: 975-80$.

27. Ramachandran $P$, Vincent $P$, Ganesh $S$, Sridharan S. Morphological abnormalities in the innervation of the atretic segment of bowel in neonates with intestinal atresia. Pediatr Surg Int 2007;23:1183-6.

28. Rømert P, Mikkelsen HB. C-kit immunoreactive interstitial cells of Cajal in the human small and large intestine. Histochem Cell Biol 1998;109:195-202.

29. Streutker CJ, Huizinga JD, Driman DK, Riddell RH. Interstitial cells of Cajal in health and disease. Part I: Normal ICC structure and function with associated motility disorders. Histopathology 2007;50:176-89.

30. Kenny SE, Connell G, Woodward MN, Lloyd DA, Gosden CM, Edgar DH, et al. Ontogeny of interstitial cells of Cajal in the human intestine. J Pediatr Surg 1999;34:1241-7. 